\title{
Psychological distress and moral injury to oncologists and their patients during COVID-19 pandemic
}

\author{
Shazia Rashid ${ }^{1}$ (1) $\cdot$ Clare Reeder $^{2} \cdot$ Satyajit Sahu $^{2} \cdot$ Sabia Rashid $^{2}$ (i) \\ Accepted: 15 July 2021 / Published online: 28 July 2021 \\ (C) The Author(s), under exclusive licence to Springer Science+Business Media, LLC, part of Springer Nature 2021
}

\begin{abstract}
The impact of the COVID-19 pandemic on healthcare systems has been unprecedented, and the psychological effects on cancer patients and health care professionals are likely to be significant and long-lasting. The traditional methods of face-to-face health care interactions have been replaced by virtual consultations to reduce exposure to COVID-19 infection. This has put the healthcare professional under tremendous psychological pressure and led to considerable anxiety and distress among cancer patients. Treatment decisions have had to be adjusted to account for a healthcare system that has been temporarily consumed by the care of people with COVID-19, and this has put cancer patients at risk of inferior outcomes. This has had the potential to cause moral injury and psychological distress to health care professionals as well as patients, who have had to deal with a range of stressors due to the uncertainty, sense of loss of control, reduced accessibility to medications and social support, changes to personal circumstances (e.g. financial pressures) and fear of death due to COVID-19 infection. Long term consequences also include post-traumatic responses and complex grief reactions. Cancer services in particular should gear themselves to recognize and monitor these effects and allocate adequate resources to combat them in the months and years to come.
\end{abstract}

Keywords COVID-19 $\cdot$ Moral injury and psychological distress $\cdot$ Mental health $\cdot$ Healthcare professionals $\cdot$ Oncologists $\cdot$ Cancer patients $\cdot$ Cancer clinicians $\cdot$ Elderly

\section{Introduction}

The coronavirus disease-2019 (COVID-19) pandemic was declared a Public Health Emergency of International Concern by the World Health Organization (WHO) on 30 January 2020. Soon the governments of major countries all over the world issued guidelines for the management of COVID-19 infection. The infection has rapidly spread around the world infecting

Shazia Rashid

srashid@amity.edu; shaziarashid123@gmail.com

Sabia Rashid

sabia.rashid1@nhs.net

Clare Reeder

clare.reeder@nhs.net

Satyajit Sahu

satyajit.sahu@nhs.net

1 Centre for Medical Biotechnology, Amity Institute of Biotechnology, Amity University Uttar Pradesh, Noida Campus, Sector-125,

Noida, Uttar Pradesh 201313, India

2 Lewisham and Greenwich NHS Trust, Queen Elizabeth Hospital, Stadium Rd, Woolwich, London SE18 4QH, UK more than 7.82 million individuals and causing more than 432,000 deaths (WHO, 2020) Both developed as well as developing countries have been affected tremendously with more damaging impacts on countries with larger populations and less infrastructure to handle this sudden pandemic. Most countries introduced a nationwide lockdown to contain the virus which had an enormous impact on the health care system.

The COVID-19 pandemic overwhelmed health care systems internationally, prompting difficult decisions and ethical dilemmas over resource allocation (Driggin et al., 2020; Pramesh \& Badwe, 2020). The pandemic caused unprecedented pressure on the hospital wards and Intensive Care Units (ICUs) and the staff who have been reassigned for the management of COVID-19 cases. Face-to-face health care encounters have been restricted to reduce exposure of COVID-19 infection to patients and providers. These restrictions are particularly relevant to patients with cancer and/or cardiovascular disease (CVD) who have a greater risk of infection and worse outcomes with COVID-19 (Ganatra et al., 2020). Due to the reduced availability of clinical services for non-COVID-19 patients, symptomatic patients have been referred from primary into secondary care (Sud et al., 2020a). 
For patients with cancer, delay of surgery has increased the likelihood of metastatic disease (Kutikov et al., 2020) and reduction in the overall survival and life-years gained (LYG) when compared to surgery under standard care (Sud et al., 2020b). Kuderer et al. (2020) reported there was no association between patient mortality and recent surgery, recent non-cytotoxic therapy, or recent cytotoxic systemic therapy that curative surgical resections, adjuvant chemotherapy, and maintenance chemotherapy could continue during the SARS-CoV-2 pandemic with extreme caution (Kuderer et al., 2020). However, some studies have reported otherwise (Liang et al., 2020; Dai et al., 2020). The situation has been further aggravated by recent safety concerns regarding aerosol generation from endoscopy, cystoscopy, and surgery (Royal College of Surgeons England, 2020). Some reports have suggested that the patients with a history of or active malignancy and receive anticancer drugs might be at increased risk of contracting the COVID-19 infection and developing COVID-19-related complications as they are immunocompromised and may develop an augmented immune response to the infection (Liang et al., 2020; Dai et al., 2020; Miyashita et al., 2020). These patients are usually older with one or more underlying health issues making them more vulnerable to COVID-19-related morbidity and mortality (Bialek et al., 2020).

\section{Perspective of Health Care Providers}

During the early stages of the pandemic, there were no clear and precise guidelines issued by the government for the health care professionals for treating cancer patients when major resources had to be diverted and allocated for the management of COVID-19 patients. This caused considerable anxiety among healthcare workers who were managing their patients outside their usual guidelines and pathways. The dilemma of patient prioritization and extent of treatment for patient cohorts who are at different stages of cancer and some having completed treatment was ambiguous. There may have been cohorts who may not have required shielding and some who were more at risk due to the underlying immune dysfunction associated with the disease itself which was further compounded by the treatment. Clinicians faced huge challenges with having to decide whether to delay investigations and treatment for some patients with so-called less acute cancer. This may have had implications on cancer progression and poor outcomes in some of these patient groups. This put clinicians at risk of moral injury, which is defined as the profound psychological distress resulting from actions (either carried out or witnessed) which violate one's moral or ethical code (Litz et al., 2009) and that can lead to deep feelings of shame, guilt, anger, and disgust. It can also contribute to other mental health problems, such as depression and
Post-traumatic Stress Disorder (PTSD) in healthcare workers (Williamson et al., 2018). As cancer patients are advised to seek consultation remotely on the phone, clinicians must assess the patient without examination which has inherent risks for the patient as well as the clinician. This is likely to lead to a negative emotional impact on clinicians' e.g. moral injury of breaking bad news over the phone; and a lack of physical cues from patients makes the sensitive empathic discussion more difficult. This is a new skill that can be tiring and anxiety-provoking. The clinician may prescribe treatment/ chemotherapy during telephone clinics which may be difficult to deliver to the patient and hence lead to dependency on the voluntary or community services. For new suspected cancer patients, clinicians are unable to make a comprehensive review for accurate diagnosis as these patients are at an increased risk of infection in a clinical setting outside their homes. The ability of staff to cope with greater levels of professional anxiety is likely to be affected by fear and anxiety relating to the possibility of acquiring the infection in a clinical setting and of passing it to the patient or their own family.

\section{Impact on Cancer Patients}

The experience of diagnosis, treatment and living with and beyond cancer is frequently experienced as traumatic and life-changing for patients and their loved ones. It impacts many areas of life including relationships, work, finances, social and leisure activities as well as physical health and well-being (e.g. pain and fatigue). Psychological distress is a common and understandable response and even in normal circumstances, in the year following diagnosis, around one in ten patients will experience symptoms of anxiety and depression severe enough to warrant intervention by specialist psychological/psychiatric services (Chong Guan et al., 2016; Cancer service guideline [CSG4]). The COVID-19 pandemic provides a second, concurrent life-altering experience, which like cancer, is associated with profound impacts on many aspects of life, including the risk of illness and death. The combination of these highly significant stressors will require significant adjustment and pose high levels of threat not only to life and physical health but also to relationships, roles, and identity.

COVID-19 is likely also to have a direct impact on the experience of cancer and its treatment. Patients may be anxious and uncertain about treatment programs that may have been put on hold, or changed, due to changing healthcare priorities in favour of COVID-19 patients and risks to cancer patients in attending hospital. They may be apprehensive about risks to themselves of contracting COVID-19 especially given their cancer diagnosis, whether their disease will progress if they agree to delay the treatment when advised by health care professionals, and if they have treatment, whether 
they will suffer side effects which may require hospital admission and thus increase the risks of getting COVID-19 infection. These experiences increase uncertainty, a sense of loss of control, and bring fears of death and dying into sharp focus, which may be amplified by the media's preoccupation with death in relation to COVID-19. Stress experienced by people with COVID-19 will be exacerbated by other related bereavements particularly if they have not had opportunities to attend funerals or gather socially to remember their loved ones.

Social support is an important factor in alleviating psychological distress in patients with cancer (Roberts et al., 1994). This is likely to be compromised due to the physical isolation resulting from COVID-19, with patients being unlikely to receive the same level of support from professionals, friends, and family. This may be particularly challenging for new patients with a cancer diagnosis who have less face to face contact with clinical nurse specialists for specialized cancer advice and support particularly in terms of managing their emotional and mental wellbeing. The general loss of coping systems e.g. social contact, outdoor exercise, travel, culture, and hobbies is likely to reduce resilience (Bauer et al., 2018) and give more time to dwell on worries at home. Loss of activity (e.g. through increased rumination) is a significant predictor of depression (De Mello et al., 2013; Nolen-Hoeksema, 2000). Also, many patients with a suspected cancer diagnosis may not seek medical help due to inaccessible face to face consultations, for fear and anxiety of contracting COVID-19 or a perception that professionals may be too busy to deal with non-urgent queries.

The relationships of cancer patients with their families are often deeply affected by cancer due, for example, to changes in roles, differences in coping styles and a range of new stressors (e.g. financial pressures) (Pitceathly \& Maguire, 2003); but additional stressors now present in terms of general increased stress and anxiety (e.g. due to loss of employment, fear of COVID-19 infection), increased time spent together in very close proximity, or family members possibly not being willing to self-isolate to the extent that may be needed to reduce risks for the person with cancer.

The shielding required of cancer patients brings additional stressors. People may have difficulty in accessing what they require to meet their basic needs, in terms of groceries or medication. Some older cancer patients may be most vulnerable due to frailty and co-morbidities: they may not be able to administer treatment themselves and need support from their pharmacist for managing their treatment. Anxiety about the risk of drug errors is frequently provoked when the medication/oral chemotherapy cycle is explained to the patient by the pharmacist for self-administration by the patient later.

Appointments during COVID-19 have been offered by phone or virtually (e.g. video-link). This may pose challenges for cancer patients in terms of lack of access to appropriate devices of communication, familiarity with the use of technology, lack of privacy at home, and reduction in clarity of communication.

For some, COVID-19 infection may have potential positive impacts. The changes to roles, restriction to activities, and general loss of social contact have affected the general population during COVID-19, not just cancer patients, and this may help people with cancer feel that they are not alone in managing adversity and risk. There may be increased support from family who may now also be at home; life may take on a slower pace for all; appointments now provided in the home rather than having to travel to the hospital, and there may be additional practical help available as communities rally to support vulnerable individuals.

\section{Impact on Carers}

The caregivers of patients with cancer frequently experience psychological distress and deterioration of general health-related quality of life (Song et al., 2011). The COVID-19 pandemic may have given many caregivers an additional sense of fear of getting infected and putting vulnerable loved ones at risk. They may not be able to be there when they are given bad news or say goodbye to dying relatives, which may lead to post-traumatic responses and complex grief reactions including feelings of guilt or anger. The parents and the carers accompanying children for cancer treatment to clinical areas fear the risk of catching the virus and the risk of transmitting to other family members, spouses, or partners. The increased general stressors relating to COVID-19 puts additional strain on carers who may already have to adjust to multiple changes (e.g. effects on finances; children at home; fear of infection). They may have to shield on behalf of relatives which would otherwise be unnecessary for them. Additionally, the worry for the person with cancer may overshadow the concerns for relatives who may have worries about own risks for contracting COVID-19 infection.

\section{Conclusion}

The full impact of the COVID-19 virus on the psychological wellbeing of cancer patients and the health care professionals looking after them maybe revealed in the months and years to come. Not only will we need to address the impact of the current crisis on existing patients and staff, but also to prepare for the presentation to health services of people with new cancer diagnoses that may be picked up at much later stages due to COVID-related delays in care and screening. This is likely to bring its own psychological challenges and risks. Some of the short- and long-term mental health risks and the recommendations for healthcare providers, cancer patients and their carers associated with COVID-19 pandemic are 
Table 1 Short- and long-term mental health risks and recommendations for healthcare providers, cancer patients and their carers associated with COVID-19 pandemic

\begin{tabular}{|c|c|c|}
\hline & Risks & Recommendations \\
\hline Healthcare providers & $\begin{array}{l}\text { - Moral injury } \\
\text { - Anxiety } \\
\text { - Depression } \\
\text { - Post-traumatic stress symptoms } \\
\text { - Burnout and compassion fatigue }\end{array}$ & $\begin{array}{l}\text { 1. Time for teams to come together to: } \\
\text { - develop a shared narrative of how difficult treatment decisions were made } \\
\text { - share coping, psycho-education and reflections on the emotional impact of the } \\
\text { work, and to encourage active monitoring of the psychological well-being of } \\
\text { selves and others } \\
\text { 2. Time to rest and recover, both for individuals and for teams together } \\
\text { 3. Training for managers on how to support teams, particularly to promote } \\
\text { psychological well-being, identifying colleagues at risk of on-going psycho- } \\
\text { logical difficulties, and active monitoring } \\
\text { 4. Psycho-education for staff on the impact of trauma, self-care and information } \\
\text { on active self-monitoring and when to seek specialist psychological inter- } \\
\text { vention } \\
\text { 5. Rapid access for specialist psychological intervention as required } \\
\text { 6. A focus of healthcare organisations on promoting psychological well-being } \\
\text { amongst staff } \\
\text { 7. Training for staff on virtual working }\end{array}$ \\
\hline $\begin{array}{l}\text { Patients with a cancer } \\
\text { diagnosis and their } \\
\text { carers }\end{array}$ & $\begin{array}{l}\text { - Social isolation } \\
\text { - Anxiety } \\
\text { - Depression } \\
\text { - Greater uncertainty } \\
\text { - Potential reduced or changed (e.g. } \\
\text { virtual) access to healthcare } \\
\text { professionals }\end{array}$ & $\begin{array}{l}\text { 2. Prioritisation of psychological well-being of patients and carers within cancer } \\
\text { services (e.g. consider provision of psychologically-informed care) } \\
\text { 2. Rapid access to specialist psycho-oncology services } \\
\text { 3. Widespread training of clinical and non-clinical patient-facing staff on basis } \\
\text { psychological assessment, engagement and communication skills } \\
\text { 4. Provision of health and well-being events which provide psycho-education on } \\
\text { the direct (e.g. social isolation) and indirect (e.g. late presentations for diag- } \\
\text { nosis) impacts of COVID-19, coping and sign-posting } \\
\text { 5. Provision of increased opportunities for social support from fellow patients } \\
\text { 6. Rapid access to practical (e.g. financial) advice and support }\end{array}$ \\
\hline
\end{tabular}

listed in Table 1. It has long been known that physical and psychological health are inextricably linked, and now, perhaps more than ever, the psychological well-being of both patients and the people who look after them should be a key priority for cancer services around the world. This may require not only increased funding for specialist psychological services to support both staff and patients with cancer and their significant others, but also an acknowledgement and commitment by health services that psychological well-being should be on a par with physical health in service planning and provision, for example in mainstream cancer services.

\section{Availability of Data and Material Not Applicable.} Code Availability Not Applicable.

Authors' Contributions Conceptualization: [Sabia Rashid], [Shazia Rashid], [Satyajit Sahu]; Investigation: [Shazia Rashid], [Clare Reeder]; Writing - original draft: [Shazia Rashid]; Writing - review \& editing: [Sabia Rashid], [Clare Reeder], [Shazia Rashid].

Funding The authors did not receive support from any organization for the submitted work.

\section{Declarations}

Conflicts of Interest/Competing Interests The authors have no relevant financial or non-financial interests to disclose.
Ethics Approval Not Applicable.

Consent to Participate Not Applicable.

Consent for Publication Not Applicable.

\section{References}

Bauer, M. R., Bright, E. E., MacDonald, J. J., Cleary, E. H., Hines, O. J., \& Stanton, A. L. (2018). Quality of life in patients with pancreatic Cancer and their caregivers: A systematic review. Pancreas, 47(4), 368-375. https://doi.org/10.1097/MPA.0000000000001025.

Bialek, S., Boundy, E., Bowen, V., Chow, N., Cohn, A., Dowling, N., Ellington, S., Gierke, R., Hall, A., MacNeil, J., Patel, P., Peacock, G., Pilishvili, T., Razzaghi, H., Reed, N., Ritchey, M., \& SauberSchatz, E. (2020) Severe Outcomes Among Patients with Coronavirus Disease 2019 (COVID-19) - United States, February 12-March 16, 2020. Morbidity and Mortality Weekly Reports, 69(12), 343-346. https://doi.org/10.15585/mmwr.mm6912e2.

Chong Guan, N., Mohamed, S., Kian Tiah, L., Kar Mun, T., Sulaiman, A. H., \& Zainal, N. Z. (2016). Psychotherapy for cancer patients. International Journal of Psychiatry in Medicine, 51(5), 414-430. https://doi.org/10.1177/0091217416680197.

Dai, M., Liu, D., Liu, M., Zhou, F., Li, G., Chen, Z., Zhang, Z., You, H., Wu, M., Zheng, Q., Xiong, Y., Xiong, H., Wang, C., Chen, C., Xiong, F., Zhang, Y., Peng, Y., Ge, S., Zhen, B., Yu, T., Wang, L., Wang, H., Liu, Y., Chen, Y., Mei, J., Gao, X., Li, Z., Gan, L., He, C., Li, Z., Shi, Y., Qi, Y., Yang, J., Tenen, D. G., Chai, L., Mucci, L. A., Santillana, M., \& Cai, H. (2020). Patients with cancer appear more vulnerable to SARS-CoV-2: A multicenter study during the 
COVID-19 outbreak. Cancer Discovery, 10(6), 783-791. https:// doi.org/10.1158/2159-8290.CD-20-0422.

De Mello, M., de Aquino, L. V., \& Antunes, H. (2013). Relationship between physical activity and depression and anxiety symptoms: A population study. Journal of Affective Disorders, 149, 241-246. https://doi.org/10.1016/j.jad.2013.01.035.

Driggin, E., Madhavan, M. V., Bikdeli, B., Chuich, T., Laracy, J., BiondiZoccai, G., Brown, T. S., der Nigoghossian, C., Zidar, D. A., Haythe, J., Brodie, D., Beckman, J. A., Kirtane, A. J., Stone, G. W., Krumholz, H. M., \& Parikh, S. A. (2020). Cardiovascular considerations for patients, health care workers, and health systems during the coronavirus disease 2019 (COVID-19) pandemic. Journal of the American College of Cardiology, 75(18), 2352 2371. https://doi.org/10.1016/j.jacc.2020.03.031.

Ganatra, S., Hammond, S. P., \& Nohria, A. (2020). The novel coronavirus disease (COVID-19) threat for patients with cardiovascular disease and cancer. J Am Coll Cardiol CardioOnc, 2(2), 350-355. https://doi.org/10.1016/j.jaccao.2020.03.001.

Kutikov, A., Weinberg, D. S., Edelman, M. J., Horwitz, E. M., Uzzo, R. G., \& Fisher, R. I. (2020). A war on two fronts: Cancer Care in the Time of COVID-19. Annals of Internal Medicine, 172(11), 756758. https://doi.org/10.7326/M20-1133.

Kuderer, N. M., Choueiri, T. K., Shah, D. P., Shyr, Y., Rubinstein, S. M., Rivera, D. R., Shete, S., Hsu, C. Y., Desai, A., de Lima Lopes Jr., G., Grivas, P., Painter, C. A., Peters, S., Thompson, M. A., Bakouny, Z., Batist, G., Bekaii-Saab, T., Bilen, M. A., Bouganim, N., Larroya, M. B., Castellano, D., del Prete, S. A., Doroshow, D. B., Egan, P. C., Elkrief, A., Farmakiotis, D., Flora, D., Galsky, M. D., Glover, M. J., Griffiths, E. A., Gulati, A. P., Gupta, S., Hafez, N., Halfdanarson, T. R., Hawley, J. E., Hsu, E., Kasi, A., Khaki, A. R., Lemmon, C. A., Lewis, C., Logan, B., Masters, T., McKay, R. R., Mesa, R. A., Morgans, A. K., Mulcahy, M. F., Panagiotou, O. A., Peddi, P., Pennell, N. A., Reynolds, K., Rosen, L. R., Rosovsky, R., Salazar, M., Schmidt, A., Shah, S. A., Shaya, J. A., Steinharter, J., StockerlGoldstein, K. E., Subbiah, S., Vinh, D. C., Wehbe, F. H., Weissmann, L. B., Wu, J. T. Y., Wulff-Burchfield, E., Xie, Z., Yeh, A., Yu, P. P., Zhou, A. Y., Zubiri, L., Mishra, S., Lyman, G. H., Rini, B. I., Warner, J. L., Abidi, M., Acoba, J. D., Agarwal, N., Ahmad, S., Ajmera, A., Altman, J., Angevine, A. H., Azad, N., Bar, M. H., Bardia, A., Barnholtz-Sloan, J., Barrow, B., Bashir, B., Belenkaya, R., Berg, S., Bernicker, E. H., Bestvina, C., Bishnoi, R., Boland, G., Bonnen, M., Bouchard, G., Bowles, D. W., Busser, F., Cabal, A., Caimi, P., Carducci, T., Casulo, C., Chen, J. L., Clement, J. M., Chism, D., Cook, E., Curran, C., Daher, A., Dailey, M., Dahiya, S., Deeken, J., Demetri, G. D., DiLullo, S., Duma, N., Elias, R., Faller, B., Fecher, L. A., Feldman, L. E., Friese, C. R., Fu, P., Fu, J., Futreal, A., Gainor, J., Garcia, J., Gill, D. M., Gillaspie, E. A., Giordano, A., Glace, (. M.). G., Grothey, A., Gulati, S., Gurley, M., Halmos, B., Herbst, R., Hershman, D., Hoskins, K., Jain, R. K., Jabbour, S., Jha, A., Johnson, D. B., Joshi, M., Kelleher, K., Kharofa, J., Khan, H., Knoble, J., Koshkin, V. S., Kulkarni, A. A., Lammers, P. E., Leighton Jr., J. C., Lewis, M. A., Li, X., Li, A., Lo, K. M. S., Loaiza-Bonilla, A., LoRusso, P., Low, C. A., Lustberg, M. B., Mahadevan, D., Mansoor, A. H., Marcum, M., Markham, M. J., Handy Marshall, C., Mashru, S. H., Matar, S., McNair, C., McWeeney, S., Mehnert, J. M., Menendez, A., Menon, H., Messmer, M., Monahan, R., Mushtaq, S., Nagaraj, G., Nagle, S., Naidoo, J., Nakayama, J. M., Narayan, V., Nelson, H. H., Nemecek, E. R., Nguyen, R., Nuzzo, P. V., Oberstein, P. E., Olszewski, A. J., Owenby, S., Pasquinelli, M. M., Philip, J., Prabhakaran, S., Puc, M., Ramirez, A., Rathmann, J., Revankar, S. G., Rho, Y. S., Rhodes, T. D., Rice, R. L., Riely, G. J., Riess, J., Rink, C., Robilotti, E. V., Rosenstein, L., Routy, B.,
Rovito, M. A., Saif, M. W., Sanyal, A., Schapira, L., Schwartz, C., Serrano, O., Shah, M., Shah, C., Shaw, G., Shergill, A., Shouse, G., Soares, H. P., Solorzano, C. C., Srivastava, P. K., Stauffer, K., Stover, D. G., Stratton, J., Stratton, C., Subbiah, V., Tamimi, R., Tannir, N. M., Topaloglu, U., van Allen, E., van Loon, S., Vega-Luna, K., Venepalli, N., Verma, A. K., Vikas, P., Wall, S., Weinstein, P. L., Weiss, M., Wise-Draper, T., Wood, W. A., Xu, W. (. V.)., Yackzan, S., Zacks, R., Zhang, T., Zimmer, A. J., \& West, J. (2020). Clinical impact of COVID-19 on patients with cancer (CCC19): A cohort study. Lancet 20, 395(10241), 1907-1918. https://doi.org/10.1016/S0140-6736(20)31187-9.

Liang, W., Guan, W., Chen, R., Wang, W., Li, J., Xu, K., Li, C., Ai, Q., Lu, W., Liang, H., Li, S., \& He, J. (2020). Cancer patients in SARSCoV-2 infection: A nationwide analysis in China. The Lancet Oncology, 21, 335-337.

Litz, B. T., Stein, N., Delaney, E., Lebowitz, L., Nash, W. P., Silva, C., \& Maguen, S. (2009). Moral injury and moral repair in war veterans: A preliminary model and intervention strategy. Clinical Psychology Review, 29, 695-706. https://doi.org/10.1016/j.cpr.2009.07.003.

Miyashita, H., Mikami, T., Chopra, N., Yamada, T., Chernyavsky, S., Rizk, D., \& Cruz, C. (2020). Do patients with cancer have a poorer prognosis of COVID-19? An experience in new York City. Annals of Oncology, 31(8), 1088-1089. https://doi.org/10.1016/j.annonc. 2020.04.006.

Nolen-Hoeksema, S. (2000). The role of rumination in depressive disorders and mixed anxiety/depressive symptoms. Journal of Abnormal Psychology, 109(3), 504-511.

Pitceathly, C., \& Maguire, P. (2003). Psychological impact of cancer on patients' partners and other key relatives: A review. European Journal of Cancer, 39(11), 1517-1524. https://doi.org/10.1016/ s0959-8049(03)00309-5.

Pramesh, C. S., \& Badwe, R. A. (2020). Cancer Management in India during Covid-19. The New England Journal of Medicine, 382(20), e61. https://doi.org/10.1056/NEJMc2011595.

Roberts, C. S., Cox, C. E., Shannon, V. J., \& Wells, N. L. (1994). A closer look at social support as a moderator of stress in breast cancer. Health \& Social Work, 19, 157-164. https://doi.org/10.1093/hsw/ 19.3.157.

Royal College of Surgeons England. (2020). Updated Intercollegiate General Surgery Guidance on COVID-19. https://www.rcseng.ac. $\mathrm{uk} /$ coronavirus/joint-guidance-for-surgeons-v2/.

Song, J. I., Shin, D. W., Choi, J. Y., Kang, J., Baik, Y. J., Mo, H., Park, M. H., Choi, S. E., Kwak, J. H., \& Kim, E. J. (2011). Quality of life and mental health in family caregivers of patients with terminal cancer. Support Care Cancer, 19(10), 1519-1526. https://doi.org/ 10.1007/s00520-010-0977-8.

Sud, A., Torr, B., Jones, M. E., Broggio, J., Scott, S., Loveday, C., Garrett, A., Gronthoud, F., Nicol, D. L., Jhanji, S., Boyce, S. A., Williams, M., Riboli, E., Muller, D. C., Kipps, E., Larkin, J., Navani, N., Swanton, C., Lyratzopoulos, G., McFerran, E., Lawler, M., Houlston, R., \& Turnbull, C. (2020a). Effect of delays in the 2-week-wait cancer referral pathway during the COVID-19 pandemic on cancer survival in the UK: A modelling study. The Lancet Oncology, 21(8), 1035-1044. https://doi.org/10.1016/ S1470-2045(20)30392-2.

Sud, A., Jones, M. E., Broggio, J., Loveday, C., Torr, B., Garrett, A., Nicol, D. L., Jhanji, S., Boyce, S. A., Gronthoud, F., Ward, P., Handy, J. M., Yousaf, N., Larkin, J., Suh, Y. E., Scott, S., Pharoah, P. D. P., Swanton, C., Abbosh, C., Williams, M., Lyratzopoulos, G., Houlston, R., \& Turnbull, C. (2020b). Collateral damage: The impact on outcomes from cancer surgery of the COVID-19 pandemic. Annals of Oncology, 31(8), 10651074. https://doi.org/10.1016/j.annonc.2020.05.009. 
Williamson, V., Stevelink, S. A. M., \& Greenberg, N. (2018). Occupational moral injury and mental health: Systematic review and meta-analysis. The British Journal of Psychiatry, 212, 339346. https://doi.org/10.1192/bjp.2018.55.

WHO (2020) WHO Director-General's opening remarks at the media briefing on COVID-19. World Health Organization. https://www. who.int/dg/speeches/detail/who-director-general-s-openingremarks-at-the-mediabriefing-on-covid-19. Accessed 20 Apr 2020.

Publisher's Note Springer Nature remains neutral with regard to jurisdictional claims in published maps and institutional affiliations. 